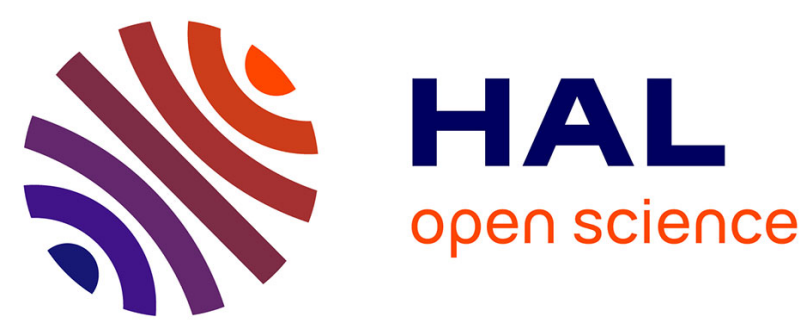

\title{
Profiling of oxygen-modulated gene expression in early human placenta by systematic sequencing of suppressive subtractive hybridization products
}

Françoise Mondon, Thérèse-Marie Mignot, Régis Rebourcet, Hélène Jammes, Jean-Louis Danan, Françoise Ferré, Daniel Vaiman

\section{To cite this version:}

Françoise Mondon, Thérèse-Marie Mignot, Régis Rebourcet, Hélène Jammes, Jean-Louis Danan, et al.. Profiling of oxygen-modulated gene expression in early human placenta by systematic sequencing of suppressive subtractive hybridization products. Physiological Genomics, 2005, 22 (1), pp.99-107. 10.1152/physiolgenomics.00276.2004 . hal-02679864

\section{HAL Id: hal-02679864 https://hal.inrae.fr/hal-02679864}

Submitted on 31 May 2020

HAL is a multi-disciplinary open access archive for the deposit and dissemination of scientific research documents, whether they are published or not. The documents may come from teaching and research institutions in France or abroad, or from public or private research centers.
L'archive ouverte pluridisciplinaire HAL, est destinée au dépôt et à la diffusion de documents scientifiques de niveau recherche, publiés ou non, émanant des établissements d'enseignement et de recherche français ou étrangers, des laboratoires publics ou privés. 
Françoise Mondon, Thérèse-Marie Mignot, Régis Rebourcet, Hélène Jammes, Jean-Louis Danan, Francoise Ferré and Daniel Vaiman

Physiol Genomics 22:99-107, 2005. First published Mar 29, 2005;

doi:10.1152/physiolgenomics.00276.2004

You might find this additional information useful...

Supplemental material for this article can be found at:

http://physiolgenomics.physiology.org/cgi/content/full/00276.2004/DC1

This article cites 33 articles, 15 of which you can access free at:

http://physiolgenomics.physiology.org/cgi/content/full/22/1/99\#BIBL

This article has been cited by 1 other HighWire hosted article:

Expressional and Epigenetic Alterations of Placental Serine Protease Inhibitors:

SERPINA3 Is a Potential Marker of Preeclampsia

S. T. Chelbi, F. Mondon, H. Jammes, C. Buffat, T.-M. Mignot, J. Tost, F. Busato, I. Gut, R.

Rebourcet, P. Laissue, V. Tsatsaris, F. Goffinet, V. Rigourd, B. Carbonne, F. Ferre and D.

Vaiman

Hypertension, January 1, 2007; 49 (1): 76-83.

[Abstract] [Full Text] [PDF]

Updated information and services including high-resolution figures, can be found at: http://physiolgenomics.physiology.org/cgi/content/full/22/1/99

Additional material and information about Physiological Genomics can be found at: http://www.the-aps.org/publications/pg

This information is current as of September 9, 2010 .

Physiological Genomics publishes results of a wide variety of studies from human and from informative model systems with techniques linking genes and pathways to physiology, from prokaryotes to eukaryotes. It is published quarterly in January, April, July, and October by the American Physiological Society, 9650 Rockville Pike, Bethesda MD 20814-3991. Copyright () 2005 by the American Physiological Society. ISSN: 1094-8341, ESSN: 1531-2267. Visit our website at http://www.the-aps.org/. 


\title{
Profiling of oxygen-modulated gene expression in early human placenta by systematic sequencing of suppressive subtractive hybridization products
}

\author{
Françoise Mondon, ${ }^{1}$ Thérèse-Marie Mignot, ${ }^{1}$ Régis Rebourcet, ${ }^{1}$ Hélène Jammes, ${ }^{1,3}$ \\ Jean-Louis Danan, ${ }^{2}$ Françoise Ferré, ${ }^{1}$ and Daniel Vaiman ${ }^{1,4}$ \\ ${ }^{1}$ Génétique et Epigénétique des Pathologies Placentaires, GEPP, U709 Institut National de la Santé et de la \\ Recherche Médicale-Université René Descartes-Institut Alfred Jost, Pavillon Baudelocque, Hôpital Cochin, \\ Paris; ${ }^{2}$ Centre National de la Recherche Scientifique UPR 9078-Université Paris V René Descartes, \\ Hôpital Necker-Enfants Malades, Paris; and ${ }^{3}$ Département de Physiologie Animale and ${ }^{4}$ Département de \\ Génétique Animale, Institut National de la Recherche Agronomique, Domaine de Vilvert, Jouy-en-Josas, France
}

Submitted 22 November 2004; accepted in final form 24 March 2005

\begin{abstract}
Mondon, Françoise, Thérèse-Marie Mignot, Régis Rebourcet, Hélène Jammes, Jean-Louis Danan, Françoise Ferré, and Daniel Vaiman. Profiling of oxygen-modulated gene expression in early human placenta by systematic sequencing of suppressive subtractive hybridization products. Physiol Genomics 22: 99-107, 2005. First published March 29, 2005; 10.1152/physiolgenomics.00276.2004.Villi from first-trimester human placenta were exposed to oxygen concentrations of either 2 or $20 \%$ during $3 \mathrm{~h}$ to construct two reciprocally subtracted libraries using the suppressive subtractive hybridization (SSH) methodology. After cloning, sequencing, and gene identification, the genes (1,071 clones corresponding to 822 different sequences) were classified according to 1 ) the subtracted library from which they originated and 2) within 58 groups of gene functions. We then developed a logarithm of the odds (LOD) test to identify a possible excess of genes in each group. We show that genes involved in angiogenesis are significantly overrepresented in the "hypoxic" condition $\left(2 \% \mathrm{O}_{2}\right)$, whereas apoptotic genes are overrepresented in the "normoxic" condition $\left(20 \% \mathrm{O}_{2}\right)$. Furthermore, we observed an excess of kinases relative to phosphatases and an excess of genes involved in proliferation over genes involved in cell growth in the hypoxic condition. To validate our results, we used quantitative RT-PCR to analyze the set of eight genes involved in angiogenesis on six independent placentas. Finally, we studied the distribution of gene clusters on human chromosomes to check whether their chromosomal distribution was random or not. We observed on human chromosome 11 a clear clustering of genes regulated similarly by $\mathrm{O}_{2}$ tension, and we also discovered indications that such clustering exists on chromosomes 6 and 12 .
\end{abstract}

hypoxia; genomic clustering; suppressive subtractive hybridization

THE PLACENTA is a gestation-specific organ that plays an essential role in the feto-maternal relationship. In humans, the placental barrier separating the maternal and fetal blood circulations is made of three different cell layers of fetal origin: the vascular endothelium, the connective tissue, and the trophoblast, comprising cytotrophoblast cells and the syncytiotrophoblast, this latter covering the villous surface and lining the maternal intervillous blood space.

It is now well established that trophoblast plugging of the maternal uterine spiral arteries and low perfusion of the inter-

Article published online before print. See web site for date of publication (http://physiolgenomics.physiology.org).

Address for reprint requests and other correspondence: D. Vaiman, Génétique et Epigénétique des Pathologies Placentaires, GEPP, U709 INSERM, Hôpital Cochin, 123 Boulevard de Port-Royal, 75014, Paris, France (e-mail: vaiman@cochin.inserm.fr). villous space until 8-12 wk of gestation protect the conceptus from the effects of high $\mathrm{O}_{2}$ levels during the crucial steps of early differentiation, when free radicals could easily damage DNA molecules and thus trigger mutations $(26,36)$. The end of the first trimester is a decisive period in which there are drastic modifications of the physicochemical conditions at the fetomaternal interface, modifications that culminate in the establishment of a fully functional hemochorial placenta, a necessary condition for the rapid growth of the human fetus during the last trimester of gestation. The specific needs of the human feto-placental unit in terms of $\mathrm{O}_{2}$ requirements, and particularly of the fetal brain (estimated to consume $50 \%$ of the $\mathrm{O}_{2}$ available for the fetus, compared with about $20 \%$ for most other mammals) have been associated with the existence of human pathologies, such as preeclampsia $(29,30)$.

In this study, we have systematically evaluated the effects of an acute and short-term lowering of $\mathrm{O}_{2}$ pressure on gene expression inside placental villi at the end of the first trimester of pregnancy. Thus we carried out a suppressive subtractive hybridization ( $\mathrm{SSH}$ ) experiment starting from cDNA material obtained from purified villi from a first-trimester placenta maintained either at $20 \%(\mathrm{O}+$ condition $)$ or at $2 \% \mathrm{PO}_{2}(\mathrm{O}-$ condition). The SSH methodology is based on a kinetic (PCRbased) subtraction of cDNAs between two physiological situations. In addition to the subtractive effect, the SSH induces a strong normalization of the cDNA libraries under scrutiny. After cloning and systematic sequencing, we could evaluate the impact of variations in $\mathrm{PO}_{2}$ on various cellular functions. We demonstrate that significant effects of hypoxia are visible on the expression of genes involved in angiogenesis and cell proliferation. Variations in the relative expression of genes coding for kinases and phosphatases were also observed, as well as an increased expression level of apoptotic genes in the $20 \% \mathrm{O}_{2}$ condition. These results were confirmed by quantitative RT-PCR analysis for 8 genes involved in angiogenesis. In addition, we have statistically studied the chromosomal distribution of $\mathrm{O}_{2}$-inhibited and $\mathrm{O}_{2}$-induced genes. We could show that large clusters of genes that share a common regulation by $\mathrm{O}_{2}$ concentration, are present on human chromosome 11. This observation suggests specific long-distance regulation mechanisms of gene expression.

\section{MATERIALS AND METHODS}

Human placental samples. All the early-gestation placentas used in this study were a gift from Cochin Hospital Maternity (Paris, France). 
Placentas were obtained from healthy women undergoing legal abortion by vacuum curettage. Six placentas were used: two at $10 \mathrm{wk}$, two at $11 \mathrm{wk}$, one at $12 \mathrm{wk}$, and one at $13 \mathrm{wk}$ of amenorrhea.

Villi preparation and hypoxia. Floating villi isolated by fine mechanical dissection were cleaned to remove fetal membranes, large vessels, and tissue of maternal origin. They were then rinsed and minced in $\mathrm{Ca}^{2+}$ - and $\mathrm{Mg}^{2+}$-free Hanks' balanced salt solution (HBSS). Villi were plated on 60-mm-diameter glass dishes $(0.4 \mathrm{~g}$ villi/dish) in $3 \mathrm{ml}$ of RPMI-1640 medium supplemented with $10 \%$ (vol/vol) fetal bovine serum, $25 \mathrm{mM}$ HEPES, $2 \mathrm{mM}$ glutamine, and antibiotics (100 IU/ml penicillin and $100 \mu \mathrm{g} / \mathrm{ml}$ streptomycin), which results in a medium height of only $1 \mathrm{~mm}$, ensuring a very rapid exchange between the atmosphere and the culture medium. They were made hypoxic by placing them at $37^{\circ} \mathrm{C}$ in a Lwoff chamber exposed to low $\mathrm{O}_{2}$ atmosphere $\left(2 \% \mathrm{O}_{2}, 5 \% \mathrm{CO}_{2}, 93 \% \mathrm{~N}_{2}\right)$ for $3 \mathrm{~h}$ after introduction of the gases into the Lwoff chamber at a flow rate of 10 $1 / \mathrm{min}$ for $15 \mathrm{~min}$. For the controls, villi were maintained at $37^{\circ} \mathrm{C}$ under normal conditions in humidified $5 \% \mathrm{CO}_{2}-95 \%$ air for $3 \mathrm{~h}$. The atmospheric $\mathrm{O}_{2}$ pressure was checked at the end of the experiment using an ABL725 gas analyzer (Radiometer, Copenhagen, Denmark). Previous experiments in our laboratory, using an Oxi $315 \mathrm{i}$ oxymeter (wtw; Fisher Bioblock Scientific, Illkirch, France), demonstrated that, after $3 \mathrm{~h}$, the $\mathrm{O}_{2}$ tension in the dish medium had equilibrated and stabilized at 15-20 Torr (unpublished observations). In addition the $\mathrm{pH}$ was checked and was not changed by the 3-h exposure to hypoxia ( $\mathrm{pH}$ 7.4). After incubation, villi were frozen in TRIzol reagent (Life Technologies, Cergy, France) for RNA isolation and stored at $-80^{\circ} \mathrm{C}$ until processing.

Total RNA, poly $(A)^{+}$preparation, and SSH. For the SSH experiment (10), the starting material was constituted by villi from an 11-wk placenta. After dissection, two batches of $2 \mathrm{~g}$ of villi from the placenta were put under either 2 or $20 \% \mathrm{O}_{2}$ during $3 \mathrm{~h}$. Total RNA was extracted from villous tissue using TRIzol reagent according to the method of Chomczynski (6). After total RNA isolation, poly(A) ${ }^{+}$was fractionated from total RNA on oligo(dT) latex beads using Macherey-Nagel columns. cDNAs were synthesized from $1.5-2 \mu \mathrm{g}$ of poly $(\mathrm{A})^{+}$using the RT of the cDNA-select kit (PCR-Select cDNA Subtraction Kit, CLONTECH). Then, after Rsal enzymatic restriction, each cDNA was divided into two batches; one was ligated to specific adaptors ("tester" DNA) and the other was left intact ("driver" DNA). Then two successive hybridizations were carried out between each tester and an excess of driver according to the manufacturer's recommendations. The first hybridization was carried out during $8 \mathrm{~h}$ and the second overnight $(14 \mathrm{~h})$. The resulting hybridized products were subjected to two PCR amplifications using oligonucleotides complementary to the adaptors, the last being a nested PCR of 15 cycles. The possible controls were performed at each step (control of the adaptor ligations, control of the GAPDH normalization). The quality of the subtraction was evaluated by PCR using primers for vascular endothelial growth factor (VEGF) (sense: 5'-ATGAACTTTCTGCTGTCTTGGGTG-3' and antisense: 5'-CTCACCGCCTCGGCTTGTCAC-3'). This gene was chosen because it is known to be highly induced in hypoxia. While the PCR product was clearly detectable by electrophoresis on an ethidium bromide-stained $2 \%$ agarose gel, after 25 PCR cycles in the hypoxia vs. normoxia SSH product (2-20 library), no signal was seen after 40 cycles in the normoxia vs. hypoxia SSH product (20-2 library, not shown).

Cloning and sequencing of SSH products. The final SSH products (originating from the nested PCR at the end of the subtraction) were cloned in the pGEMT vector (Promega) by incubation of $300 \mathrm{ng}$ of each of the PCR products with $50 \mathrm{ng}$ of vector with $1 \mu \mathrm{l}$ of T4 DNA ligase (Biolabs) in the appropriate buffer for $48 \mathrm{~h}$ at $4^{\circ} \mathrm{C}$, in a total volume of $20 \mu \mathrm{l}$. The ligation mixtures were diluted to the fifth in sterile water and used to transform lab-prepared DH10B electrocompetent Escherichia coli bacteria with a Biolabs electroporator. The transformation titer was evaluated on 8-cm LB-agar plates prepared with $100 \mu \mathrm{g} / \mathrm{ml}$ ampicillin and isopropylthiogalactoside/X-Gal (21), and the next day $\sim 1,500$ colonies from each of the two subtractions were plated on $22 \times 22$-cm LB-agar trays. After an overnight growth, colonies were manually picked and grown individually in 96-well megaplates containing $1 \mathrm{ml} \mathrm{LB} \cdot 100 \mu \mathrm{g}^{-1} \cdot \mathrm{ml} \mathrm{ampicillin}{ }^{-1}$ and $10 \%$ glycerol. The plates were covered with porous covers and grown overnight at $37^{\circ} \mathrm{C}$ under rocking at $200 \mathrm{rpm}$. Two hundred microliters were then kept in 96 -well microtiter plates at $-80^{\circ} \mathrm{C}$. Sequencing was carried out by transferring a frozen aliquot of the bacteria to $3 \mathrm{ml}$ $\mathrm{LB} \cdot 100 \mu \mathrm{g}^{-1} \cdot \mathrm{ml} \mathrm{ampicillin}^{-1}$. After an overnight growth, the plasmid DNA was isolated by classical miniprep and sequenced using an ABI 16 capillaries sequencer. The sequences obtained were blasted against the National Center for Biotechnology Information (NCBI) library (http://www.ncbi.nlm.nih.gov/). The known gene function [Gene Ontology (GO) annotation information] was then systematically recorded, as well as the chromosomal location in megabases.

Quantitative RT-PCR analysis. Quantitative RT-PCR was carried out by use of the Roche LightCycler Fast Start Syber Green I kit in $15-\mu 1$ reaction volumes, using the InvitroGen quantitative PCR kit with primers designed for each gene with the Primer3 software (available at http://frodo.wi.mit.edu/cgi-bin/primer3/primer3_www.cgi). The list of primers and PCR conditions are presented in Table 1 . PCR amplification was followed by a melting curve rising from 65 to $99^{\circ} \mathrm{C}$ in $10 \mathrm{~min}$ with a continuous measure of the fluorescence intensity, enabling analysis of the purity of the PCR product for each couple of primers. This purity and the molecular weight and length of the amplified DNA were further assessed by electrophoresing the PCR products on 3\% ethidium bromide-stained agarose gels.

Statistical analysis of differences between expected and observed gene categories. Genes were classified according to their functions and were grouped into three categories: genes found once or more than once only in the 2-20 library ("hypoxic" genes), genes found once or more than once only in the 20-2 library ("normoxic" genes), and genes found in both libraries ("insensitive" genes). After classification of the genes according to their functions, the total number of hits per function was recorded. To assess the significance of these observed totals, we estimated the expected number of genes in each of the three categories (hypoxic, normoxic, insensitive) by multiplying the sum of genes in each group by the percentage of specific hypoxic, normoxic, and insensitive genes in the whole set of sequences. Two separate analyses were then carried out: either considering that the genes belong to one of the three possible categories or considering only the two categories hypoxic and normoxic. The probabilities of obtaining a given number of genes were thus calculated using either a multinomial (three categories) or binomial (two categories) law.

Table 1. Primer sequences for quantitative RT-PCR

\begin{tabular}{lc}
\hline \hline \multicolumn{1}{c}{ Primer Name } & \multicolumn{1}{c}{ Primer Sequence } \\
\hline THBS.1 & ACTCAGACCGCATTGGAGAT \\
THBS.2 & GTCATCATCGTGGTCACAGG \\
ANGPTL.1 & GGGTCTGGAGAAGGTGCATA \\
ANGPTL4.2 & GTCCCAAGTGGAGAAGGTA \\
IL8.1 & GTGCAGTTTTGCCAAGGAGT \\
IL8.2 & AATTTCTGTGTTGGCGCAGT \\
QKI.1 & TCAGGGAAGATTGGTCACA \\
QKI.2 2 AMOTL2.1 & AAATCAAAGCCAGAAGGTG \\
AMOTL2.2 & GCCAGACACTCATTCCCATT \\
FLT1.1 & GGCTGAATCCTCATTCTCCA \\
FLT1.2 & TGTGGAAGAAAGGCAAACA \\
IGF2.1 & ACGAGCTCCCTTCCTTCAGT \\
IGF2.2 & TCCTCCCTGGACAATCAGAC \\
IL24.1 & AGAAGCACCAGCATCGACTT \\
IL24.2 & GAACCTTCCACCCACAGCTA \\
\hline
\end{tabular}

Melting temperature $=58^{\circ} \mathrm{C}$. PCR conditions were as follows: $50^{\circ} \mathrm{C}$ for 2 min, initial denaturation at $94^{\circ} \mathrm{C}$ for $2 \mathrm{~min}$, cycling at $58^{\circ} \mathrm{C}$, denaturation at $94^{\circ} \mathrm{C}$ for $5 \mathrm{~s}, 58^{\circ} \mathrm{C}$ for $15 \mathrm{~s}$, and $72^{\circ} \mathrm{C}$ for $20 \mathrm{~s}$. 
These values were compared by a LOD score test considering that above $\operatorname{LOG}(20 / 1) \sim 1.301$; the values were significant at the $5 \%$ threshold.

Statistical analysis of gene distribution in the hypoxic or normoxic clusters. This analysis was achieved by counting in each chromosome the number of consecutive hypoxic $(\mathrm{H})$ or normoxic $(\mathrm{N})$ genes, therefore enabling us to count the number of singletons (i.e., genes that are framed by genes or group of genes that are not regulated in the same way, for instance NNHNN or $\mathrm{HNHH}$ ) and groups of two, three, four, and so forth, contiguous genes identically regulated. The distribution of the groups was then compared with a random distribution obtained by a Monte Carlo simulation where 1,000 random orders were worked out by the computer, each of these orders being evaluated for the number of singletons and groups of two or more consecutive genes regulated in the same fashion.

\section{RESULTS}

Characterization of the two SSH libraries. The two SSH libraries were constructed from mRNA originating from the same placenta maintained during $3 \mathrm{~h}$ either at 2 or $20 \% \mathrm{O}_{2}$ (see MATERIALS AND METHODS). After SSH and PCR amplification, the two products were ligated and cloned into two distinct sublibraries. The two sublibraries will be referred to as "2-20" and "20-2," as stated in MATERIALS AND METHODS, without reference to the normal $\mathrm{O}_{2}$ status of placental villi at the end of the first trimester, since many studies indicate that the normal $\mathrm{O}_{2}$ pressure is low in the maternal intervillous space, in front of the placental villi at early stages of pregnancy (see DISCUSSION).

One thousand seven hundred fifty clones were sequenced, 1,071 of which resulted in exploitable gene sequences. These sequences were aligned systematically against the NCBI database. The other sequences were empty clones, poly(A) stretches, or unreadable sequences. Eight hundred twenty-two different genes could be identified, 454 in the 2-20 library and 319 in the 20-2 library, while 49 were present in both libraries.

These sequences were classified according to their redundancy (Fig. 1). This clearly demonstrated that a large majority of the genes $(80.4 \%)$ were present only once in the complete set of sequenced clones, while $14.7 \%$ were present twice. These proportions reflect the normalizing effect of the SSH procedure. This was also confirmed by the RT-PCR analysis of GAPDH transcripts, which exhibited a 3,000-fold reduction in the subtracted products. To test the efficiency of the two $\mathrm{O}_{2}$ conditions in modulating the expression of specific genes in terms of RNA levels, VEGF was used as a well-known marker induced by hypoxia (14). While a band was clearly detectable after 25 PCR cycles in the "2-20" SSH product, no signal could be seen after 40 cycles in the "20-2" SSH product (data not shown). The effects of the $\mathrm{O}_{2}$ concentration on gene expression were also evaluated by comparing the consistency of the presence of clones occurring more than once in the two libraries. Forty-nine sequences were found more than once in both libraries, while 112 clones were found more than once specifically in one library only, which corresponds to a highly significant excess $\left(P=6.8 \times 10^{-7}\right)$. This confirms the effect of the subtraction between the two normoxic and hypoxic states of the villi. Among the most frequent sequences found in both libraries, and therefore encoding genes affected slightly, if at all, by the $\mathrm{O}_{2}$ pressure, the $\alpha$-chain of the chorionic gonadotrophins (CGA) was found in 15 occurrences, the ubiquitous eukaryotic translation elongation factor- $1 \alpha 1$ (EE1F1A1) in 9 occurrences, and the extracellular matrix component fibronectin-1 (FN1) in 9 occurrences.

Transcripts found consistently in one library only encode proteins involved in various cellular functions. Seven transcripts were found more than three times in the 20-2 library, while thirteen were found more than three times in the 2-20 library. Among those, three encode mitochondrial proteins: $A T P 5 B, C O X 1$, and the gene encoding the VAL tRNA (Table 2). Other mitochondrial genes were also found induced in the 2-20 library, supporting the idea that mitochondria react very early to $\mathrm{O}_{2}$ pressure changes in human trophoblasts, as well as for other cell types (9). By contrast, two genes involved in hemoglobin activity [ferritin, heavy polypeptide-1 (FTHI), an important iron transporter, and fem 1 homolog c (FEMIC), known as a transcriptional inducer of fetal globin synthesis] were found twice and four times, respectively, in both libraries, however. This suggests that genes involved in globin function are somehow independent from $\mathrm{O}_{2}$ pressure conditions, at least in early placentas. This also suggests that the role of $\mathrm{O}_{2}$ sensors is mainly assigned to mitochondria in the placental villi. The other genes from the 2-20 library found in three occurrences or more were involved in other functions, such as angiogenesis (quaking homolog; $Q K I$ ), lipid transport and adipocyte differentiation (adipophilin; $A D F P$ ), inhibition of protein degradation (serine protease inhibitor E2; SERPINE2), and immunomodulation in the placenta (pregnancy-specific glycoprotein-4; PSG4). Intriguingly, the WBSCRl gene involved in the Williams-Beuren syndrome occurred four times in the 2-20 library.

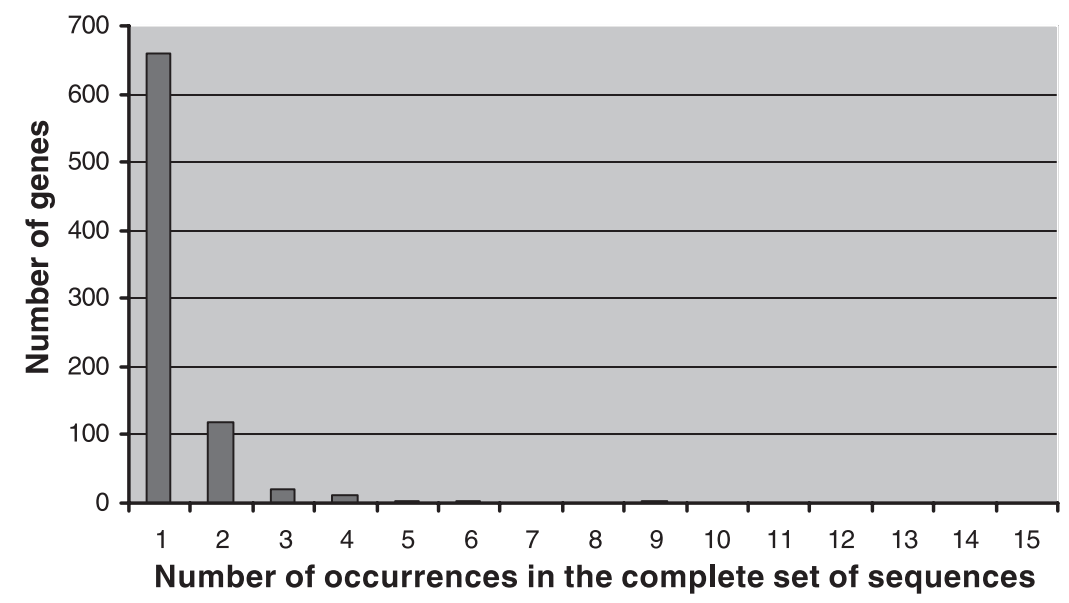

Fig. 1. Histogram of gene representation after the suppressive subtractive hybridization (SSH) procedure. Most genes are present only once in the library $(80.4 \%)$; genes present once or twice represent $95.1 \%$ of the clones, emphasizing the normalizing effect of the method. 
Table 2. Genes found consistently in more than three occurrences

\begin{tabular}{|c|c|c|c|c|}
\hline & 3 Occurrences & 4 Occurrences & 5 Occurrences & 6 Occurrences \\
\hline
\end{tabular}

Boldface text indicates genes encoding mitochondrial proteins.

The Williams-Beuren syndrome leads to a mild mental retardation in children sometimes endowed with a specific musical talent (21). Interestingly, BAZ1B, also called WBSCR9, also belongs to the minimal chromosomal region deleted in this disease (35) and was found once in the 2-20 library. Altogether these observations indicate the existence of a placental participation in this syndrome.

Systematic analysis of the function of the sequenced genes. To further analyze our raw sequencing results, the genes were categorized in 58 groups or subgroups of functions according to their known biological role(s), according to the GO categories (GO database). This made it possible to distribute the genes from the 20-2 and the 2-20 libraries into functional groups as well as those present in both libraries (insensitive, called "mixed;" see Supplemental Table S1, available at the Physiological Genomics web site). ${ }^{1}$

When analyzing the three gene categories, significant discrepancies appeared between the observed and expected occurrences for genes involved in numerous functions (22 functions among 58 had a significant LOD score; see Table 3).

The high number of statistically significant categories obtained when analyzing together the three categories prompted us to develop a more stringent analysis by focusing only on the 2-20 and 20-2 categories and comparing them by a LOD score test, enabling us to compare the expected and the observed frequency of the genes found in each functional category (Table 3). In this case, the number of categories exhibiting a significant discrepancy from what was expected dropped to two. They encompass genes involved in angiogenesis (LOD = 2.19) and genes involved in apoptosis regulation (LOD = 1.45). Close to significance were genes involved in favoring apoptosis $(\mathrm{LOD}=1.19)$, genes involved in protein synthesis and ribosome function $(\mathrm{LOD}=1.00)$, and genes of unknown function $(\mathrm{LOD}=1.22)$.

These significant LOD values result from an excess of "hypoxic genes" in the angiogenesis and "unknown function" categories. They also reflect an excess of "normoxic genes" for genes involved in apoptosis and for genes specifically favoring apoptosis, as well as for genes involved in protein biosynthesis and ribosomal function.

${ }^{1}$ The Supplemental Material for this article (Supplemental Table S1) is available online at http://physiolgenomics.physiology.org/cgi/content/full/ 00276.2004/DC1.)
To further analyze the sequencing data, we contrasted pairs of gene groups acting in opposite biological functions (for instance, genes involved in amino acid phosphorylation vs. amino acid dephosphorylation, genes favoring apoptosis vs. genes protecting against apoptosis, etc.). The analysis was performed using $\chi^{2}$-tests between the actual number of genes and the expected number calculated from a $2 \times 2$ contingency table (Table 4). A significant $\chi^{2}$-test value $(P=0.03)$ was obtained while contrasting genes involved in phosphorylation vs. genes involved in dephosphorylation, with an excess of kinases in the 2-20 library (hypoxic condition). Another significant $\chi^{2}$-test value $(P=0.02)$ was observed while comparing genes involved in cell growth and differentiation with genes involved in cell proliferation, the latter appearing in higher numbers than expected statistically in the hypoxic condition.

Quantitative RT-PCR analysis of the expression of genes involved in angiogenesis in the early placenta. To quantify more accurately the increase in transcription of the genes belonging to the categories harboring a significant discrepancy between the two libraries, we decided to focus our interest on angiogenic genes that were found exclusively in the hypoxic part of the SSH clones (2-20 library). We analyzed the expression of ANGPTL4, AMOTL2, IGF2, IL8, IL24, QKI, THBS1, and FLTI (which is one of VEGF receptors) by quantitative RT-PCR. We used cDNA prepared from the villi of six early placentas (before $13 \mathrm{wk}$ of amenorrhea), and we analyzed the effect of hypoxia vs. normoxia for every individual placental sample maintained during $3 \mathrm{~h}$ in 2 or $20 \% \mathrm{O}_{2}$.

An important issue was the selection of a normalizing gene that was not affected by hypoxia in the early placenta. We decided to use $C G A$ as a reporter gene because it is the most commonly found in the libraries, with a relatively equilibrated number of occurrences. Therefore, the number of cycles corresponding to the initiation of the linear portion of the amplification curves $(\mathrm{C} 0)$ of each sample was systematically subtracted by the $\mathrm{C} 0$ value obtained for $C G A$ of the same sample. We compared the "normoxia" situation against the "hypoxia" situation by a paired Student's $t$-test. Significant values were obtained for THBS1, FLT1, IGF2, QKI, IL8, AMOTL2, and ANGPTL4. Altogether, all the genes studied were induced by exposure to $2 \% \mathrm{O}_{2}$ for $3 \mathrm{~h}$. The ratios of induction were 2.2 , 2.7, 4.6, 2.9, 2.7, 1.3, 6.3, and 4.8, respectively, for THBS1, 
Table 3. Comparison between observed and expected gene nos. In each functional category

\begin{tabular}{|c|c|c|c|c|c|c|c|c|c|}
\hline & \multicolumn{4}{|c|}{$\begin{array}{l}\text { Observed Occurrences Computed from } \\
\text { Proportions of Different Groups }\end{array}$} & \multicolumn{3}{|c|}{$\begin{array}{l}\text { Expected Occurrences Computed from } \\
\text { Proportions of Different Groups }\end{array}$} & \multirow{2}{*}{$\begin{array}{c}\text { LOD } \\
\text { Scores } \\
\text { on the } 3 \\
\text { Categories }\end{array}$} & \multirow{2}{*}{$\begin{array}{l}\text { LOD Scores } \\
\text { for Comparing } \\
\text { Hypoxic vs. } \\
\text { Normoxic } \\
\text { Categories }\end{array}$} \\
\hline & Mixed & Normoxic & Hypoxic & Total & Mixed & Normoxic & Hypoxic & & \\
\hline Amino acid phosphorylation/dephosphorylation & 4 & 24 & 30 & 58 & 9.63 & 20.8 & 27.6 & 1.07 & 0.01 \\
\hline Dephosphorylation/phosphatase & 0 & 8 & 5 & 13 & 2.16 & 4.65 & 6.19 & 1.42 & 0.39 \\
\hline Protein kinase/kinase associated & 4 & 14 & 26 & 44 & 7.31 & 15.8 & 20.9 & 0.68 & 0.23 \\
\hline Angiogenesis & 2 & 0 & 9 & 11 & 1.83 & 3.94 & 5.23 & 2.19 & 2.19 \\
\hline Apoptosis regulation & 7 & 21 & 11 & 39 & 6.48 & 14 & 18.6 & 1.46 & 1.45 \\
\hline Apoptosis + & 5 & 16 & 8 & 29 & 4.82 & 10.4 & 13.8 & 1.19 & 1.19 \\
\hline Apoptosis - & 2 & 6 & 5 & 13 & 2.16 & 4.65 & 6.19 & 0.13 & 0.13 \\
\hline Blood coagulation & 4 & 4 & 2 & 10 & 1.66 & 3.58 & 4.76 & 0.97 & 0.30 \\
\hline Carbohydrate metabolism & 6 & 5 & 13 & 24 & 3.99 & 8.59 & 11.4 & 0.62 & 0.38 \\
\hline Cell adhesion/cell-cell signaling & 18 & 11 & 26 & 55 & 9.13 & 19.7 & 26.2 & 2.45 & 0.59 \\
\hline Cell cycle & 6 & 18 & 15 & 39 & 6.48 & 14 & 18.6 & 0.40 & 0.39 \\
\hline Cell cycle + & 2 & 4 & 5 & 11 & 1.83 & 3.94 & 5.23 & 0.01 & 0.00 \\
\hline Cell cycle - & 4 & 11 & 6 & 21 & 3.49 & 7.52 & 9.99 & 0.73 & 0.71 \\
\hline Cell growth/maintenance/proliferation & 14 & 21 & 36 & 71 & 11.8 & 25.4 & 33.8 & 0.29 & 0.19 \\
\hline Cell growth/maintenance + & 3 & 15 & 11 & 29 & 4.82 & 10.4 & 13.8 & 0.70 & 0.50 \\
\hline Cell growth/maintenance - & 0 & 4 & 5 & 9 & 1.49 & 3.22 & 4.28 & 0.71 & 0.00 \\
\hline Cell proliferation & 11 & 7 & 20 & 38 & 6.31 & 13.6 & 18.1 & 1.51 & 0.73 \\
\hline Chemotaxis & 0 & 1 & 2 & 3 & 0.5 & 1.07 & 1.43 & 0.26 & 0.03 \\
\hline Chromatin organization and modification & 2 & 5 & 13 & 20 & 3.32 & 7.16 & 9.52 & 0.54 & 0.38 \\
\hline Cytoskeleton organization and biogenesis & 15 & 27 & 26 & 68 & 11.3 & 24.3 & 32.4 & 0.59 & 0.30 \\
\hline DNA engineering & 0 & 21 & 20 & 41 & 6.81 & 14.7 & 19.5 & 3.48 & 0.25 \\
\hline Ethanol oxidation & 0 & 0 & 1 & 1 & 0.17 & 0.36 & 0.48 & 0.32 & 0.24 \\
\hline Extracellular matrix & 4 & 2 & 9 & 15 & 2.49 & 5.37 & 7.14 & 0.87 & 0.66 \\
\hline Fatty acid and lipid metabolism & 0 & 7 & 20 & 27 & 4.48 & 9.67 & 12.8 & 2.86 & 0.73 \\
\hline General metabolism and energy & 25 & 18 & 35 & 78 & 13 & 27.9 & 37.1 & 2.81 & 0.39 \\
\hline Glycolysis & 6 & 2 & 4 & 12 & 1.99 & 4.3 & 5.71 & 1.59 & 0.05 \\
\hline Hematopoiesis & 3 & 0 & 3 & 6 & 1 & 2.15 & 2.86 & 1.50 & 0.73 \\
\hline Hormone metabolism & 15 & 11 & 9 & 35 & 5.81 & 12.5 & 16.7 & 3.15 & 0.25 \\
\hline Androgen receptor metabolism & 0 & 1 & 1 & 2 & 0.33 & 0.72 & 0.95 & 0.16 & 0.01 \\
\hline Immune response & 22 & 19 & 29 & 70 & 11.6 & 25.1 & 33.3 & 2.06 & 0.05 \\
\hline Inflammatory response & 2 & 2 & 2 & 6 & 1 & 2.15 & 2.86 & 0.23 & 0.02 \\
\hline Ion/electron transport/binding & 18 & 48 & 64 & 130 & 21.6 & 46.5 & 61.9 & 0.16 & 0.00 \\
\hline Calcium ion & 6 & 7 & 13 & 26 & 4.32 & 9.31 & 12.4 & 0.27 & 0.11 \\
\hline Zinc ion & 4 & 18 & 30 & 52 & 8.64 & 18.6 & 24.7 & 0.91 & 0.13 \\
\hline Iron metabolism & 6 & 4 & 3 & 13 & 2.16 & 4.65 & 6.19 & 1.46 & 0.12 \\
\hline Learning and memory & 0 & 1 & 0 & 1 & 0.17 & 0.36 & 0.48 & 0.44 & 0.36 \\
\hline Mitosis & 0 & 4 & 2 & 6 & 1 & 2.15 & 2.86 & 0.77 & 0.30 \\
\hline Mobility/motility & 18 & 12 & 19 & 49 & 8.14 & 17.5 & 23.3 & 2.54 & 0.05 \\
\hline Myoblast fusion & 2 & 0 & 0 & 2 & 0.33 & 0.72 & 0.95 & 1.55 & 0.00 \\
\hline Oxydoreductase/NO synthesis & 3 & 7 & 5 & 15 & 2.49 & 5.37 & 7.14 & 0.27 & 0.25 \\
\hline Proteolysis, proteasome, ubiquitination & 2 & 23 & 47 & 72 & 12 & 25.8 & 34.3 & 3.76 & 0.65 \\
\hline Proteasome activity & 0 & 18 & 29 & 47 & 7.81 & 16.8 & 22.4 & 3.79 & 0.09 \\
\hline Peptidase & 2 & 4 & 10 & 16 & 2.66 & 5.73 & 7.61 & 0.31 & 0.27 \\
\hline Peptidase protection & 0 & 2 & 8 & 10 & 1.66 & 3.58 & 4.76 & 1.30 & 0.51 \\
\hline Protein biosynthesis and ribosome & 31 & 25 & 55 & 111 & 18.4 & 39.7 & 52.8 & 2.93 & 1.00 \\
\hline Pregnancy & 0 & 0 & 0 & $\mathbf{0}$ & 0 & 0 & 0 & 0.00 & 0.00 \\
\hline Protein binding/modification & 13 & 42 & 61 & 116 & 19.3 & 41.5 & 55.2 & 0.63 & 0.04 \\
\hline Response to oxidative stress (and others) & 2 & 12 & 13 & 27 & 4.48 & 9.67 & 12.8 & 0.49 & 0.06 \\
\hline Nonoxidative stress & 2 & 6 & 6 & 14 & 2.33 & 5.01 & 6.66 & 0.06 & 0.05 \\
\hline Oxidative stress & 0 & 4 & 2 & 6 & 1 & 2.15 & 2.86 & 0.77 & 0.30 \\
\hline RNA processing/splicing and binding & 20 & 37 & 44 & 10 & 16.8 & 36.2 & 48.1 & 101.64 & 0.05 \\
\hline Signal transduction & 27 & 55 & 70 & 152 & 25.2 & 54.4 & 72.3 & 0.04 & 0.01 \\
\hline Skeletal/cartilage development & 3 & 2 & 7 & 12 & 1.99 & 4.3 & 5.71 & 0.49 & 0.37 \\
\hline Transcription regulation & 11 & 40 & 53 & 10 & 17.3 & 37.2 & 49.5 & 106.43 & 0.00 \\
\hline Transcription + & 0 & 2 & 0 & 2 & 0.33 & 0.72 & 0.95 & 0.89 & 0.73 \\
\hline Transcription - & 2 & 6 & 6 & 14 & 2.33 & 5.01 & 6.66 & 0.06 & 0.05 \\
\hline Transport & 4 & 42 & 44 & 90 & 14.9 & 32.2 & 42.8 & 3.06 & 0.26 \\
\hline Unknown & 10 & 76 & 68 & 154 & 25.6 & 55.1 & 73.3 & 4.30 & 1.22 \\
\hline
\end{tabular}

Boldface text indicates totals and significant LOD score values.

FLT1, IGF2, QKI, IL8,IL24, ANGPTL4, and AMOTL2 (Fig. 2).

Clustering of genes similarly regulated by $\mathrm{O}_{2}$ pressure. We used the complete set of sequences to locate on the chromo- somes the genes found during the experiment. We tested whether the genes were dispersed at random or clustered, according to their induction or repression by $\mathrm{O}_{2}$ for every human chromosome. This was performed by a simulation 
Table 4. Contingency tables and significant $\chi^{2}$ values for matched gene categories

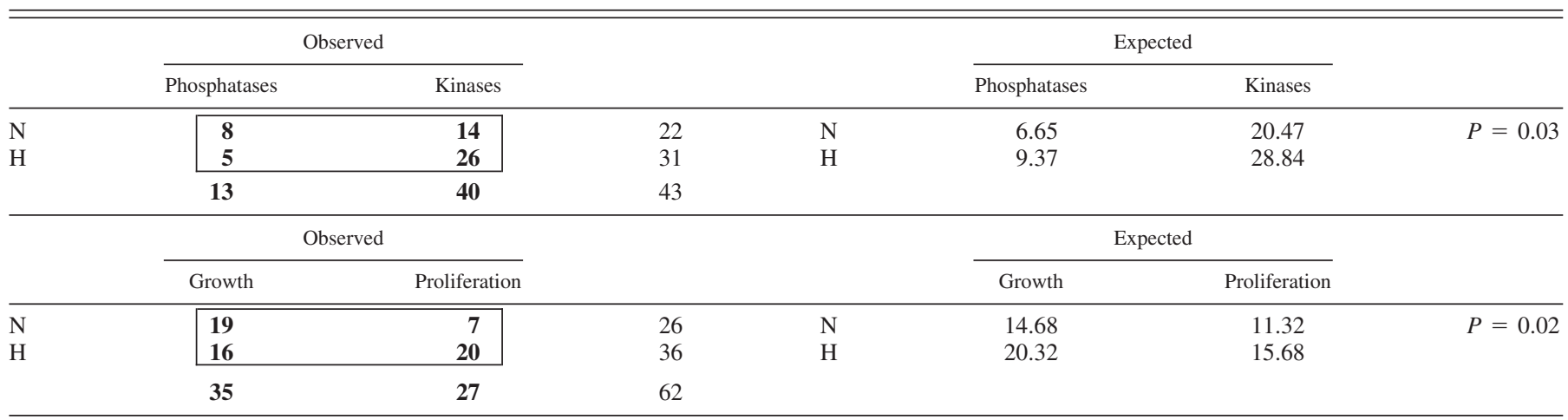

Boldface text indicates the observed no. of genes in each category. N, normoxic; H, hypoxic.

approach involving the generation of 1,000 random gene orders, as described in MATERIAL AND METHODS. Using this approach, we could evaluate the global clustering of hypoxic and normoxic genes, and we could also compare each class according to the number of clusters of a given number of genes. When the classes were compared at the chromosome level by a $\chi^{2}$-analysis (grouping classes if necessary to achieve a number of at least 5 genes in the theoretical class), we obtained a significant test only for human chromosome 11 (HSA11) $(P=$ $0.037)$. In addition to this global test, we performed an intraclass test by comparing the obtained value with the 1,000 simulations. By this method, we could confirm that HSA11 was significantly depleted in singletons $(P=0.036)$ and significantly in excess for groups of five consecutive genes homogenously regulated, i.e., found in the same SSH library of clones $(P=0.001)$. These results for HSA11 are summarized in Fig. 3. When applying the same strategy, we could also detect significant values for HSA6 (depleted in singletons, $P=$ 0.04 ) and for HSA12. This last chromosome has a trend toward a depletion in singletons $(P=0.07)$ and contains a group of seven consecutive hypoxia-induced genes $(P=0.027)$.

\section{DISCUSSION}

In this paper, we studied the alterations in gene expression that occur in human early placental villi exposed to a short period ( $3 \mathrm{~h}$ ) of hypoxia ( $2 \%$ oxygen) by the SSH method. The dissected placental villi were kept for $3 \mathrm{~h}$ only in hypoxia to identify mainly genes involved in an acute response to hypoxia. The biological significance of such a short exposure is relevant at the placental level, since in early pregnancies, acute and local variations of oxygen pressure are supposed to occur
Fig. 2. Real-time PCR analysis of genes found by the SSH procedure to be hypoxia induced and specific for angiogenesis. Fig. 2 has been divided into 2 parts, to take into account the fact that the basal and induced levels of expression are very different for the genes analyzed. The results are given in folds of induction deduced from the $\mathrm{C} 0$ values (for explanation of C0 values, see RESUlTS) of the real-time PCR, subtracted by the $\alpha$-chain of the chorionic gonadotrophins (CGA) $\mathrm{C} 0$ values, $C G A$ being taken as a reporter gene. Statistical comparisons were performed by a paired $t$-test to compare for each of the 6 placentas studied the levels of expression in normoxia and in hypoxia. Significant values obtained for 7 genes among 8 are presented.

\section{A}

Fold induction after $3 \mathrm{~h}$ of hypoxia

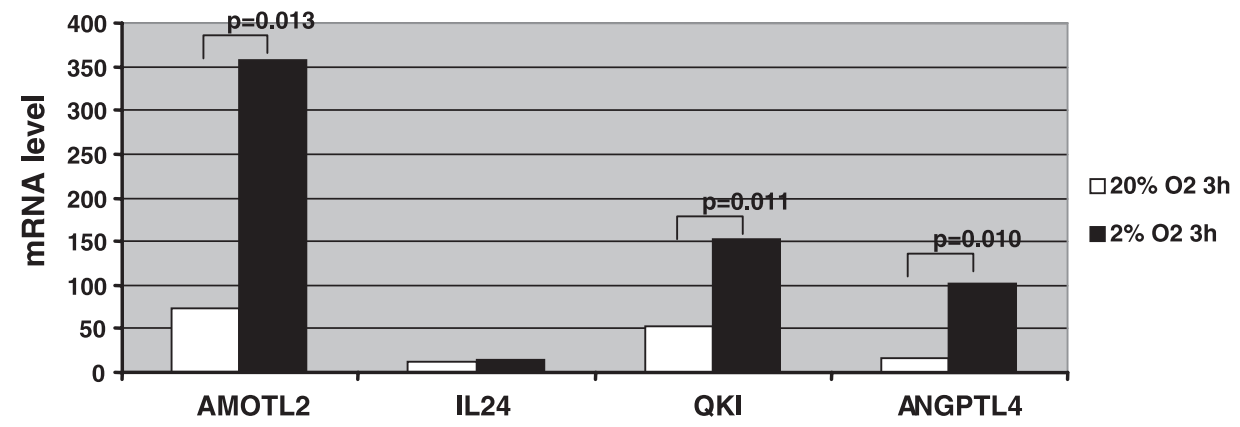

B Fold induction after $3 \mathrm{~h}$ of hypoxia

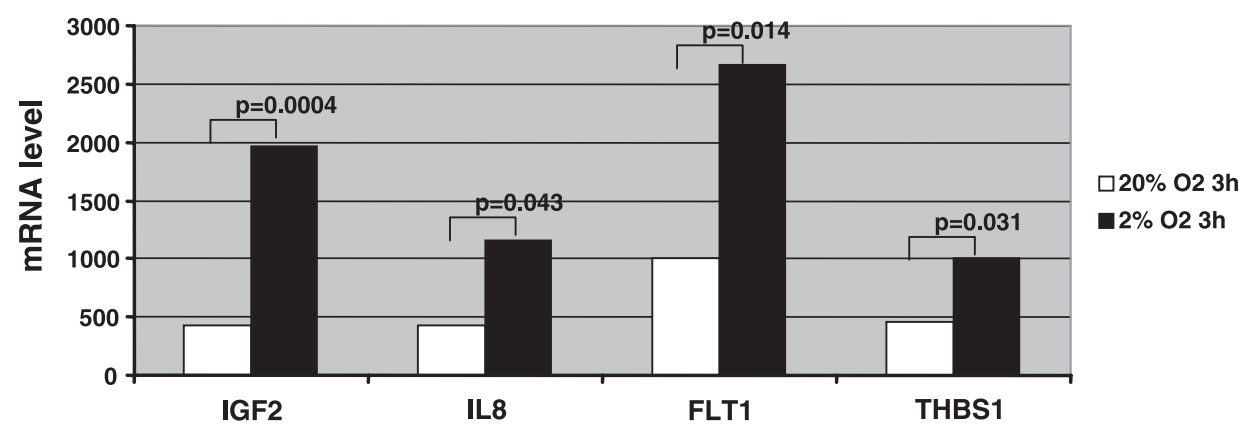

Physiol Genomics • VOL 22 • www.physiolgenomics.org 
Expected vs. Observed groups of co-regulated genes on HSA11

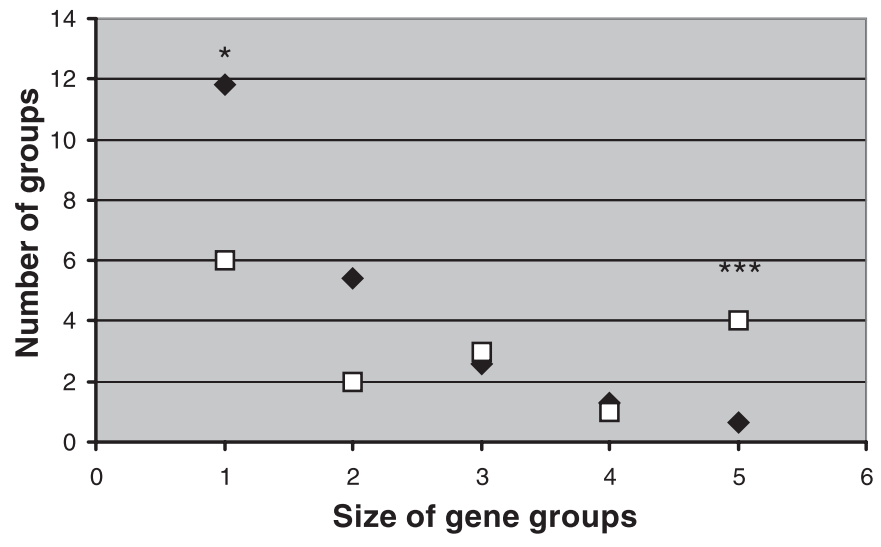

Fig. 3. Analysis of the clustering of "hypoxic/normoxic" genes on human chromosome 11 (HSA11). Squares represent the actual number of clusters observed on the chromosome and are classified according to their size (no. of "normoxic" or "hypoxic" consecutive genes). Diamonds represent the expected no. of clusters, according to 1,000 random repetitions of a Monte Carlo simulation (see MATERIALS AND METHODS). The extreme classes [singletons and 5 consecutive genes] appear significantly under- or overrepresented in the actual data set, respectively. See RESULTS for statistical thresholds.

naturally at the feto-maternal interface. Most of these events will not be prolonged toward a genuine ischemic accident but could in some cases be a starting point of the installation of a long-standing oxygen depletion leading ultimately to a placental vascular disease such as preeclampsia. Therefore, identifying early modifications of gene expression due to an acute but short oxygen depletion could point out relevant early markers of placental disease. Three hours correspond to a short but sufficient duration for allowing the oxygen tension to equilibrate with the atmospheric pressure in the medium, as we and others have demonstrated (1). An additional interest in using such short exposure resides in the fact that, after a 3-h lap, factors such as cell death and necrosis will not be relevant.

Several studies indicate that the normal oxygen pressure of the intervillous space in front of placental villi at early stages of pregnancy is low [estimated at $20 \mathrm{mmHg}(2.6 \%)$ around 8 wk of gestation, but rising to $50 \mathrm{mmHg}(6.6 \%)$ at $12 \mathrm{wk}$ and to $60 \mathrm{mmHg}(7.9 \%)$ at the middle of the second trimester; Refs. $16,22,34]$. At the anatomic level, this first-trimester hypoxia is due to a plug of cytotrophoblasts present in the distal part of the anchoring villi that forms several columns of cells. This proliferation is associated with physiological hypoxic conditions (19). Aside from the fetal oxygen consumption, the placental consumption has been evaluated at $\sim 50 \%$ of the total input, one-half of which is involved in oxidative phosphorylations in mitochondria $(5,23,32)$.

In our experiment, the placenta used for the SSH was $11 \mathrm{wk}$ old, suggesting that the villi were exposed to a genuine but moderate hypoxia compared with physiological conditions. This is illustrated by the fact that the VEGF transcript was differentially enriched in the two reciprocal SSH libraries. The signal was visible after 25 cycles of PCR, which shows that even in the 2-20 library, VEGF is not a frequent transcript. This substantiates the observation of Kumazaki et al. (20), who could barely detect the VEGF mRNA in hypoxic/ischemic placentas while the protein was clearly detectable by immunohistochemistry.
We based our analysis on placental villi, a native tissue composed of several cell types (cytotrophoblasts, syncytiotrohoblast, endothelial cells, lymphocytes, macrophages, vascular smooth muscle cells, etc.). This approach is common in the field $(15,27)$ and enables one to spot differences that are representative of the complexity of the physiological situation, although the use of complex tissue mainly reveals large differences affecting relevant biological markers, as a specific cell type may adapt to ameliorate the overall increase or decrease of expression. Complementary studies analyzing the transcriptome of specific cell types can be performed in the future to help specify which cell types are involved in the activation of a given gene. The recent study of Ning et al. (25) was based on the serial analysis of gene expression (SAGE) of endothelial cell transcriptome alterations under hypoxia. Although the groups of genes represented in this study are similar to ours, the size of the groups differs. The authors discovered specific alterations of heat shock factors, glycolytic enzymes, extracellular matrix factors, cytoskeletal factors, apoptotic factors, cell cycle regulators, and angiogenic factors.

We used an approach based on the systematic sequencing of the SSH products and gene analysis by functional categories. The choice of using SSH was based on the assumption that we would be able to discover factors expressed at a lower level than genes classically detected (33). This approach has been successful, since we could demonstrate that a short exposure to hypoxia is able to modify a group of important cellular functions known to be of particular relevance in early placenta when oxygen pressure varies. In a first step, we based our analysis on the genes divided into three categories: insensitive, hypoxic, and normoxic. However, in this analysis, the high number of significant differences in various biological functions was attributable to a marked discrepancy between the expected and observed number of genes in the insensitive category. For instance, for genes involved in proteasome activity, eight genes were theoretically expected but none could be found. This means that the genes implicated in this function were never found simultaneously in both libraries. Similarly, genes involved in transcriptional regulation or genes of unknown function were much less abundant than expected in the mixed category, suggesting that they can be found in hypoxia as well as in normoxia. However, each of them clearly appears to be determined by the oxygen status. Among transcriptional factors that were found more than once in the 2-20 library (hypoxia induced), we find ZNF83, QKI, SQSTM1, and HIP2. The fact that transcription factors appear clearly determined by the oxygen concentration implies that both conditions (hypoxic and normoxic) could be induced by two specific families of transcription factors. Therefore, a new analysis was performed, considering only the genes that were found exclusively in one physiological state. This allowed us to drastically reduce the number of significantly different cellular functions. One of the classes most clearly identified as "hypoxia induced" was angiogenesis. There is abundant literature about the effects of oxygen on placental vasculogenesis and angiogenesis (see, for instance, Refs. 9, 11, 14, 18, 20, 28, 38). However, most of these studies have focused on factors known to be involved in hypoxia sensing and vasculo/angiogenesis, such as VEGF, VEGFR1 (FLT-1), VEGFR2 (KDR), ANG-1, ANG-2, TIE, and $P l G F$. In our clones, only FLT- 1 belongs to this category, but we could also discover lesser-known actors, such as AMOTL2, 
ANGPTL4, and THBS1. Therefore, our SSH approach suggests interesting new targets for future studies. Similarly, it was not at all unexpected to identify genes involved in cell proliferation, as the normal hypoxic conditions pertaining at the tip of first-trimester placental villi are triggering the proliferation of cytotrophoblasts in cell columns, previous to their transformation in invading cytotrophoblasts. In parallel, cytotrophoblasts of the floating villi also have the potential of becoming proliferative at the end of the first trimester, showing that the low oxygen concentration at the intervillous space affects all these cells (2). The molecular basis of this proliferation and changes of phenotype is not as well elucidated as those of the angiogenesis pathways in the early placenta. Therefore, the genes we have identified constitute interesting candidates for further studies. The discovery of an excess of apoptotic genes in the 20-2 library is also indicative of the general status of the tissue, where a relative hypoxia may appear as the normal situation. Contrary to the other significant functions that were uncovered by our approach, the excess of kinases over phosphatases in the 2-20 library has not been previously described in the literature. The significance of this excess remains to be explored at the individual gene level.

In addition to our results on gene expression, we have shown that there seems to be a high-level organization of gene function in wide chromosome regions. This is particularly the case for HSA11. One of the four hypoxia-inducible regions of more than five consecutive genes found on this chromosome corresponds to the well-known cluster of imprinted genes found at $11 \mathrm{p} 15.5$. This substantiates the importance of this gene cluster for placental physiology, and particularly the importance of IGF2 and $\mathrm{H} 19$ as major actors of correct placental development $(8,31)$. Our findings add another dimension showing that external factors may contribute to the regulation of gene expression. This is further strengthened by the sequence analysis of the promoters of $H 19$ and $I G F 2$, which displays an extreme richness in $\mathrm{CpG}$ islands and putative HIF $1 \alpha$-binding sites. The existence of coregulated gene clusters in eukaryotic genomes is becoming substantiated by an increasing number of reports $(4,7)$. The explanation of such a long-range regulation remains to be clarified but will probably be accessible in the near future by techniques of chromatin analysis, which recently have been applied successfully to the Igf2/H19 region in mice (24).

In conclusion, our approach made it possible to identify the cellular functions in the first-trimester placental villi that are strongly modified by a short exposure to particular concentrations of oxygen, as well as the functions that remain unchanged. The relevance of studying the effects of oxygen at the end of the first trimester is clear, since oxygen is recognized at this stage as critically important for a successful colonization of maternal uterine arteries by invasive trophoblasts (17). This is consistent with the fact that, during the first trimester, the low level of endovascular trophoblastic invasion leads to a minimal maternal blood flow to the placenta and therefore to the creation of a hypoxic environment, concomitant with a very high level of placental development, compared with that of the embryo $(12,13)$. During the invasion, the plugs of cytotrophoblasts are expelled and the cells encounter a positive oxygen pressure gradient that may play an important part in the differentiation of invasive cytotrophoblast cells and their relocalization in the media of maternal uterine blood vessels. This colonization of the mother circulation is thought to be the key pathway leading to the loss of the contractile properties of maternal uterine spiraled arteries and hence toward the input of a considerable amount of blood and nutrients in direction of the feto-placental unit (17). Indeed, many experimental results substantiate the major role of oxygen pressure in the normal physiology of cytotrophoblast cells. It is possible to hypothesize that chronic hypoxia at this stage may constitute an early indication of risk for the major placental pathologies preeclampsia and intrauterine growth retardation. Surprisingly, only a few studies have been performed that analyze the effects of oxygen on gene expression in placental villi. A recent study by Tsui et al. (37) makes use of commercially available microarrays and identifies several genes that appear as markers of preeclampsia. However, commercial arrays do not make it possible to easily identify rare transcripts such as transcription factors that may be relevant for explaining the physiology of complex diseases. The complementary roles of SSH and microarrays have recently been thoroughly analyzed in a study (3) involving the in vitro differentiation of human monocytes to myeloid dendritic cells. In this study, SSH products were used as probes for hybridizations on Affymetrix DNA chips (3). It clearly demonstrates that both techniques are complementary and make it possible to discover different sets of genes. We hope the present study will contribute to the identification of new factors that may become powerful tools for deciphering the complexities of placental physiopathology.

\section{REFERENCES}

1. Allen CB, Schneider BK, and White CW. Limitations to oxygen diffusion and equilibration in in vitro cell exposure systems in hyperoxia and hypoxia. Am J Physiol Lung Cell Mol Physiol 281: L1021-L1027, 2001.

2. Aplin JD, Haigh T, Jones CJ, Church HJ, and Vicovac L. Development of cytotrophoblast columns from explanted first-trimester human placental villi: role of fibronectin and integrin- $\alpha 5 \beta 1$. Biol Reprod 60: 828-838, 1999.

3. Cao W, Epstein C, Liu H, DeLoughery C, Ge N, Lin J, Diao R, Cao H, Long F, Zhang X, Chen Y, Wright PS, Busch S, Wenck M, Wong K, Saltzman AG, Tang Z, Liu L, and Zilberstein A. Comparing gene discovery from Affymetrix GeneChip microarrays and Clontech PCRselect cDNA subtraction: a case study. BMC Genomics 5: 26, 2004.

4. Caron H, van Schaik B, van der Mee M, Baas F, Riggins G, van Sluis P, Hermus MC, van Asperen R, Boon K, Voute PA, Heisterkamp S, van Kampen A, and Versteeg $\mathbf{R}$. The human transcriptome map: clustering of highly expressed genes in chromosomal domains. Science 291: 1289-1292, 2001.

5. Carter AM. Placental oxygen consumption. Part I: in vivo studies-a review. Placenta 21, Suppl A: S31-S37, 2000.

6. Chomczynski P. A reagent for the single-step simultaneous isolation of RNA, DNA and proteins from cell and tissue samples. Biotechniques 15: 532-534, 536-537, 1993.

7. Cosseddu GM, Perez-Enciso M, Fellous M, and Vaiman D. Interspecific chromosome-wide transcription profiles reveal the existence of mammalian-specific and species-specific chromosome domains. J Mol Evol 59: 317-328, 2004.

8. DeChiara TM, Robertson EJ, and Efstratiadis A. Parental imprinting of the mouse insulin-like growth factor II gene. Cell 64: 849-859, 1991.

9. De Marco CS and Caniggia I. Mechanisms of oxygen sensing in human trophoblast cells. Placenta 23, Suppl A: S58-S68, 2002.

10. Diatchenko L, Lau YF, Campbell AP, Chenchik A, Moqadam F, Huang B, Lukyanov S, Lukyanov K, Gurskaya N, Sverdlov ED, and Siebert PD. Suppression subtractive hybridization: a method for generating differentially regulated or tissue-specific cDNA probes and libraries. Proc Natl Acad Sci USA 93: 6025-6030, 1996.

11. Dunk C, Shams M, Nijjar S, Rhaman M, Qiu Y, Bussolati B, and Ahmed A. Angiopoietin-1 and angiopoietin-2 activate trophoblast Tie-2 
to promote growth and migration during placental development. Am J Pathol 156: 2185-2199, 2000.

12. Genbacev $\mathbf{O}$. To proliferate or to divide-to be or not to be. Early Pregnancy 5: 63-64, 2001.

13. Genbacev $\mathbf{O}$ and Miller RK. Post-implantation differentiation and proliferation of cytotrophoblast cells: in vitro models-a review. Placenta 21, Suppl A: S45-S49, 2000.

14. Geva E, Ginzinger DG, Zaloudek CJ, Moore DH, Byrne A, and Jaffe RB. Human placental vascular development: vasculogenic and angiogenic (branching and nonbranching) transformation is regulated by vascular endothelial growth factor-A, angiopoietin-1, and angiopoietin-2. J Clin Endocrinol Metab 87: 4213-4224, 2002.

15. Gratton RJ, Gluszynski M, Mazzuca DM, Nygard K, and Han VK. Adrenomedullin messenger ribonucleic acid expression in the placentae of normal and preeclamptic pregnancies. J Clin Endocrinol Metab 88: 6048-6055, 2003.

16. Jauniaux E, Watson A, and Burton G. Evaluation of respiratory gases and acid-base gradients in human fetal fluids and uteroplacental tissue between 7 and 16 weeks' gestation. Am J Obstet Gynecol 184: 998-1003, 2001.

17. Kaufmann P, Black S, and Huppertz B. Endovascular trophoblast invasion: implications for the pathogenesis of intrauterine growth retardation and preeclampsia. Biol Reprod 69: 1-7, 2003.

18. Kaufmann P, Mayhew TM, and Charnock-Jones DS. Aspects of human fetoplacental vasculogenesis and angiogenesis. II. Changes during normal pregnancy. Placenta 25: 114-126, 2004.

19. Kingdom JC and Kaufmann P. Oxygen and placental villous development: origins of fetal hypoxia. Placenta 18: 613-621; discussion 623616, 1997.

20. Kumazaki K, Nakayama M, Suehara N, and Wada Y. Expression of vascular endothelial growth factor, placental growth factor, and their receptors Flt-1 and KDR in human placenta under pathologic conditions. Hum Pathol 33: 1069-1077, 2002.

21. Lashkari A, Smith AK, and Graham JM Jr. Williams-Beuren syndrome: an update and review for the primary physician. Clin Pediatr (Phila) 38: 189-208, 1999.

22. Maltepe E and Simon MC. Oxygen, genes, and development: an analysis of the role of hypoxic gene regulation during murine vascular development. J Mol Med 76: 391-401, 1998.

23. Mover-Lev H, Dreval D, Zakut H, and Ar A. $\mathrm{O}_{2}$ consumption in the in-vitro fetal side human placenta. Respir Physiol 106: 199-208, 1996.

24. Murrell A, Heeson S, and Reik W. Interaction between differentially methylated regions partitions the imprinted genes Igf2 and H19 into parent-specific chromatin loops. Nat Genet 36: 889-893, 2004.
25. Ning W, Chu TJ, Li CJ, Choi AM, and Peters DG. Genome-wide analysis of the endothelial transcriptome under short-term chronic hypoxia. Physiol Genomics 18: 70-78, 2004.

26. Potter CF, Kuo NT, Farver CF, McMahon JT, Chang CH, Agani FH, Haxhiu MA, and Martin RJ. Effects of hyperoxia on nitric oxide synthase expression, nitric oxide activity, and lung injury in rat pups. Pediatr Res 45: 8-13, 1999.

27. Rajakumar A, Doty K, Daftary A, Harger G, and Conrad KP. Impaired oxygen-dependent reduction of HIF- $1 \alpha$ and $-2 \alpha$ proteins in pre-eclamptic placentae. Placenta 24: 199-208, 2003.

28. Regnault TR, de Vrijer B, Galan HL, Davidsen ML, Trembler KA, Battaglia FC, Wilkening RB, and Anthony RV. The relationship between transplacental $\mathrm{O}_{2}$ diffusion and placental expression of PlGF, VEGF and their receptors in a placental insufficiency model of fetal growth restriction. J Physiol 550: 641-656, 2003.

29. Robillard PY, Dekker GA, and Hulsey TC. Evolutionary adaptations to pre-eclampsia/eclampsia in humans: low fecundability rate, loss of oestrus, prohibitions of incest and systematic polyandry. Am J Reprod Immunol 47: 104-111, 2002.

30. Robillard PY, Hulsey TC, Dekker GA, and Chaouat G. Preeclampsia and human reproduction. An essay of a long term reflection. J Reprod Immunol 59: 93-100, 2003.

31. Sasaki H, Ferguson-Smith AC, Shum AS, Barton SC, and Surani MA. Temporal and spatial regulation of H19 imprinting in normal and uniparental mouse embryos. Development 121: 4195-4202, 1995.

32. Schneider H. Placental oxygen consumption. Part II: in vitro studies-a review. Placenta 21, Suppl A: S38-S44, 2000.

33. Seta KA and Millhorn DE. Functional genomics approach to hypoxia signaling. J Appl Physiol 96: 765-773, 2004.

34. Soothill PW, Nicolaides KH, Rodeck CH, and Campbell S. Effect of gestational age on fetal and intervillous blood gas and acid-base values in human pregnancy. Fetal Ther 1: 168-175, 1986.

35. Tassabehji M. Williams-Beuren syndrome: a challenge for genotypephenotype correlations. Hum Mol Genet 12: R229-R237, 2003.

36. Tolle A, Kolleck I, Schlame M, Wauer R, Stevens PA, and Rustow B. Effect of hyperoxia on the composition of the alveolar surfactant and the turnover of surfactant phospholipids, cholesterol, plasmalogens and vitamin E. Biochim Biophys Acta 1346: 198-204, 1997.

37. Tsui NB, Chim SS, Chiu RW, Lau TK, Ng EK, Leung TN, Tong YK, Chan KC, and Lo YM. Systematic micro-array based identification of placental mRNA in maternal plasma: towards non-invasive prenatal gene expression profiling. J Med Genet 41: 461-467, 2004.

38. Zygmunt M, Herr F, Munstedt K, Lang U, and Liang OD. Angiogenesis and vasculogenesis in pregnancy. Eur J Obstet Gynecol Reprod Biol 110, Suppl 1: S10-S18, 2003. 